\title{
Karakterisasi Bionanofiller Dari Limbah Serbuk Kayu Meranti Sebagai Pengisi Pada Polimer Komposit
}

\author{
Maria Ulfah $^{1}$, Sri Aprilia, ${ }^{2, *}$, Fauzi M. Djuned ${ }^{2}$ \\ ${ }^{1}$ Program Magister Teknik Kimia, Fakultas Teknik, Universitas Syiah Kuala \\ ${ }^{2}$ Jurusan Teknik Kimia, Fakultas Teknik, Universitas Syiah Kuala \\ Jl. Tgk. Syech Abdul Rauf No. 7, Darussalam, Banda Aceh, Indonesia
}

*Koresponden Email: sriaprilia@unsyiah.ac.id

\begin{abstract}
Utilization of wood powder is one of the alternative in waste wood prevention which has not been optimally utilized. Utilization of bionanofiller based on wood waste such as wood powder can also reduce dependence on raw materials such as silica, clay, bentonite, zeolite which diminished its existence. The sample used in this study is Meranti wood powder which is then prepared and characterized. The characterization of bionanofiller waste of Meranti wood powder is done by analyzing particle density, XRD, SEM, and FTIR. Particle density analysis showed Meranti wood powder having density of $0,044 \mathrm{gr} / \mathrm{cm}^{3}$. XRD analysis shows that the maximum peak at an angle of $2 \theta$ $=22,2^{\circ}$ indicates the presence of carbon phase. The results of SEM analysis of Meranti wood powder are suitable for use as fillers because they are $1 \mu \mathrm{m}$ in size. The result of functional group analysis shows the presence of functional groups $-\mathrm{OH},-\mathrm{CH} 3,-\mathrm{CH} 2, \mathrm{C}=\mathrm{C}, \mathrm{C}-\mathrm{H}$ and $\mathrm{C}-\mathrm{O}$.
\end{abstract}

Keywords: bionanofiller, preparation, density

Abstrak. Pemanfaatan serbuk kayu adalah salah satu alternatif dalam penanggulangan limbah kayu yang mana selama ini belum dapat dimanfaatkan secara optimal. Pemanfaatan bionanofiller yang berbasis limbah kayu seperti serbuk kayu juga dapat mengurangi ketergantungan terhadap bahan baku seperti silika, clay, bentonit, zeolit yang semakin berkurang keberadaannya. Sampel yang digunakan pada penelitian ini adalah serbuk kayu Meranti yang kemudian dipreparasi dan dikarakterisasi. Karakterisasi bionanofiller limbah serbuk kayu Meranti ini dilakukan dengan menganalisis densitas partikel, XRD, SEM, dan FTIR. Analisis densitas partikel menunjukkan serbuk kayu Meranti memiliki densitas sebesar $0,044 \mathrm{gr} / \mathrm{cm}^{3}$. Analisis XRD menunjukkan puncak maksimum terdapat pada sudut $2 \theta$ $=22,2^{\circ}$ menunjukkan adanya fasa karbon. Hasil anlisis SEM dari serbuk kayu Meranti layak digunakan sebagai filler karena sudah berukuran $1 \mu \mathrm{m}$. Hasil analisis gugus fungsi menunjukkan adanya gugus fungsi $-\mathrm{OH},-\mathrm{CH}_{3},-\mathrm{CH}_{2}, \mathrm{C}=\mathrm{C}, \mathrm{C}-\mathrm{H}$ dan $\mathrm{C}-\mathrm{O}$.

Kata kunci : bionanofiller, preparasi, densitas

\section{Pendahuluan}

Teknologi hijauatau teknologiramah lingkungan pada saat ini semakin serius dikembangkan oleh negara-negara di dunia. Hal ini menjadikan suatu tantangan yang terus diteliti oleh para pakar untuk dapat mendukung kemajuan teknologi ini. Salah satunya adalah teknologi komposit yang berpenguat biomassa. Tuntutan teknologi ini disesuaikan juga dengan keadaan alam yang mendukung untuk pemanfaatannya secara optimal (Nurudin dkk., 2011).

Pemanfaatan limbah pertanian seperti limbah serbuk kayu sebagai penguat pada bionanokomposit disebabkan karena ketersediaan bahan baku 
Tabel 1. Komposisi kimia kayu meranti

\begin{tabular}{|c|c|}
\hline Kumponeu Kimiı & Kadur lol \\
\hline L.jgnin & 51.45 \\
\hline Sclulosa & 31,62 \\
\hline Pentosan & 24,12 \\
\hline Abu & 0.86 \\
\hline Silikil & 0,86 \\
\hline
\end{tabular}

Sumber : Sari dkk (2009)

yang sangat melimpah di alam, biodegredable, mempunyai kekuatan dan modulus yang kuat, biaya rendah, ekspansi termal rendah dan sangat ramah lingkungan.

Perkembangan ilmu pengetahuan dan riset diperlukan adanya penelitian yang terus menerus terhadap bahan komposit, baik itu dari segi analisis, perancangan dan proses pembuatannya sehingga menjadikannya sebagai suatu bahan yang unggul (Azwar, 2009).

Di samping itu perkembangan teknologi dan ilmu pengetahuan di segala bidang telah menuntut tersedianya bahan teknik sebagai faktor pendukung yang utama. Bahan-bahan teknik konvensional yang berasal dari alam yang tidak dapat diperbaharui (non biodegradable) sangat terbatas persediaannya sehingga perlu dicari alternatif bahan-bahan teknik non konvensional yang dapat diperbaharui (biodegradable). Sebagian besar material konvensional mempunyai sifat yang homogen dan isontropik, sedangkan material non konvesional mempunyai sifat tidak homogen dan anisotropic. Bahan komposit adalah salah satu bahan non konvensioanal yang sifatnya tergantung dari arah dan posisi penyusunnya.

Penemuan bahan komposit adalah sebagai revolusi terbesar dalam dunia ilmu material, hal

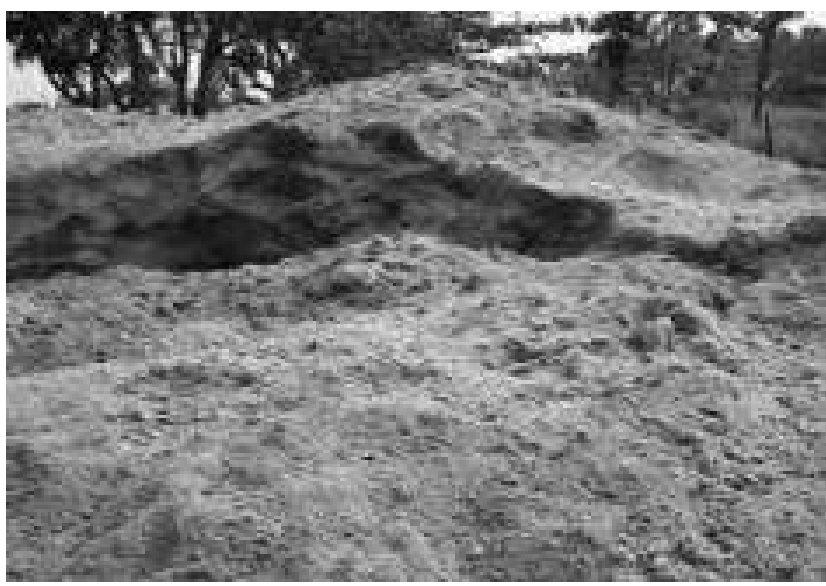

Gambar 1. Serbuk kayu/serbuk gergaji ini disebabkan karena bahan komposit mampu bersaing dengan bahan konvensional lainnya. Bahan komposit mempunyai kekuatan dan kekakuannya sama dengan baja, akan tetapi bahan komposit lebih ringan hingga $70 \%$.

Kayu merupakan jenis tumbuhan tropis yang sangat banyak dijumpai di Indonesia. Hasil dari proses industri kayu (hasil penggergajian) sering menghasilkan limbah padat berupa serbuk kayu dan serpihan kayu. Limbah kayu ini selalu terbuang dan menumpuk di suatu tempat tertentu sehingga mengganggu kondisi lingkungan sekitar. Oleh sebab itu perlu dilakukan penanganan lebih lanjut terhadap limbah padat hasil penggergajian kayu tersebut.

Kayu adalah material yang mempunyai sifat anisotropic dan higroskopis yang berperan penting dalam ilmu material dengan struktur makro yang berbentuk serat. Sebagian besar kayu terdiri dari selulosa (40-50\%), hemiselulosa (20$30 \%$ ), dan lignin (20-30\%). Kayu mempunyai beberapa sifat yang tidak dapat ditiru oleh bahan lainnya. Serat kayu yang digunakan untuk filler sangat tergantung dari jenis kayu yang digunakan (Azwar., 2009).

Meranti adalah jenis kayu yang berasal dari marga sorea dari suku dipterocarpaceae. Meranti tergolong kayu keras berbobot ringan sampai berat sedang yang mempunyai densitas berkisar antara $0,3-0,86 \mathrm{~g} / \mathrm{cm}^{3}$ de $\mathrm{ng}$ a $\mathrm{n}$ kandungan air sekitar 15\% (berat jenis adalah perbandingan relatif antara massa jenis sebuah zat dengan massa jenis air murni). Kayu terasnya berwarna merah muda pucat, merah muda kecoklatan, hingga merah tua atau bahkan merah tua kecoklatan. Berdasarkan berat jenisnya, kayu meranti terdiri dari meranti merah muda yang lebih ringan dan meranti merah tua yang lebih berat. Komposisi kimia kayu meranti dapat dilihat pada Tabel 1.

Di Indonesia ada tiga macam industri yang secara dominan mengkonsumsi kayu dalam jumlah yang relatif besar, yaitu : penggergajian, vinir atau kayu lapis, dan pulp atau kertas. Sejauh ini, limbah biomassa dari industri tersebut sebagian ada yang dimanfaatkan kembali dalam proses pengolahannya sebagai bahan bakar guna 


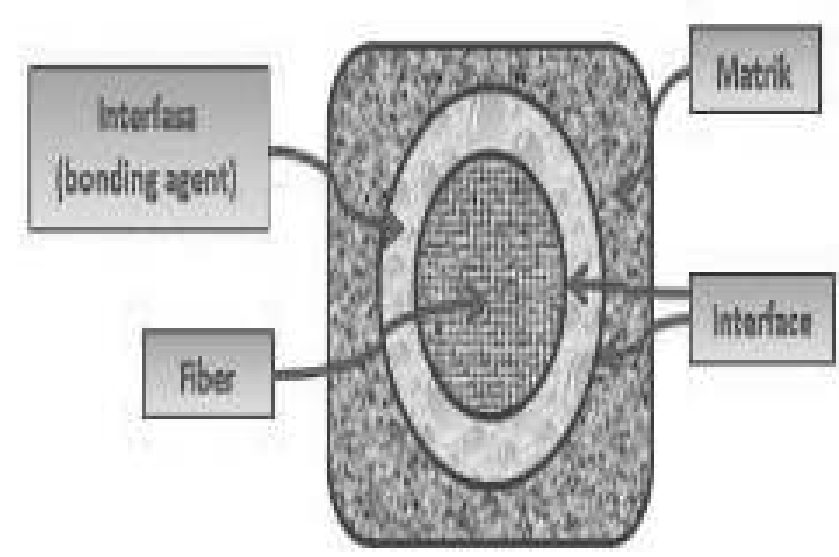

Gambar 2. Ilustrasi material penyusun komposit

melengkapi kebutuhan energinya. Kenyataannya, saat ini masih ada limbah penggergajian kayu yang ditimbun dan sebagian dibuang ke aliran sungai sehingga terjadi pencemaran air. Selain itu ada juga yang membakarnya secara langsung sehingga menambah emisi karbon di atmosfer.

Produksi total kayu gergajian Indonesia mencapai 2,6 juta $\mathrm{m}^{3}$ pertahun, dengan asumsi bahwa jumlah limbah yang terbentuk 54,24 persen dari produksi total. Oleh karena itu, maka dihasilkan limbah penggergajian kayu sebanyak 1,4 juta $\mathrm{m}^{3}$ pertahun dan angka ini cukup besar karena mencapai sekitar separuh dari produksi kayu gergajian (Pari, G., 2002).

Melihat dari kondisi tersebut dan sejalan dengan kebijakan yang diterapkan oleh Kementerian Lingkungan Hidup dan Kehutanan, maka diperlukan penanganan lebih lanjut terhadap limbah serbuk kayu atau serbuk gergaji tersebut. Pemanfaatan limbah serbuk gergajian kayu secara optimal menghasilkan suatu produk yang lebih bermutu dan bernilai jual tinggi (Sudrajat dan Pari, 2011).

Pemanfaatan limbah serbuk kayu sebagai bionanofiller merupakan salah satu alternatif dalam meningkatkan daya guna suatu bahan. Pemanfaatan bionanofiller dari serbuk kayu juga dapat mengurangi ketergantungan terhadap bahan baku seperti silika, clay, bentonit, zeolit yang semakin berkurang keberadaannya. Selain itu juga bionanofiller dari serbuk kayu jika dipadukan dengan matriks polimer dapat menghasilkan material komposit yang ramah lingkungan (Slamet, 2013).

Di Provinsi Aceh khususnya Kabupaten Pidie serbuk kayu mempunyai potensi yang sangat besar untuk dijadikan sebagai filler karena selama ini limbah serbuk kayu hasil gergajian pemanfaatannya masih belum optimal. Kebanyakan dari limbah kayu tersebut hanya digunakan sebagai bahan bakar yang memiliki nilai ekonomi yang rendah.

Filler adalah bahan pengisi yang digunakan dalam pembuatan komposit, biasanya berupa serat atau serbuk. Serat yang sering digunakan dalam pembuatan komposit antara lain serat E-Glass, Boron, Carbon dan lain sebagainya. Bisa juga dari serat alam antara lain serat kenaf, jute, rami, cantula dan lain sebagainya.

Penggunaan nanofiller sebagai penguat pada polimer komposit memiliki beberapa keuntungan yaitu biayanya rendah, sumber daya alam yang dapat diperbaharui, sifat-sifat khusus, density rendah, mudah dalam preparasi, membutuhkan energi yang rendah untuk proses, biodegradabel, penggunaan yang luas dan relatif non-abrasi dibandingkan dengan penguatan dengan bahan tradisional (Kim dkk, 2007; Menconen dkk, 2013).

Pada awalnya filler yang digunakan sebagai penguat pada polimer matrix adalah berasal dari bahan anorganik (La Mantia, 2005). Alasan utama penggunaan filler adalah harga yang murah atau untuk peningkatan sifat-sifat polimer matriks seperti; rigiditas, ketahanan terhadap

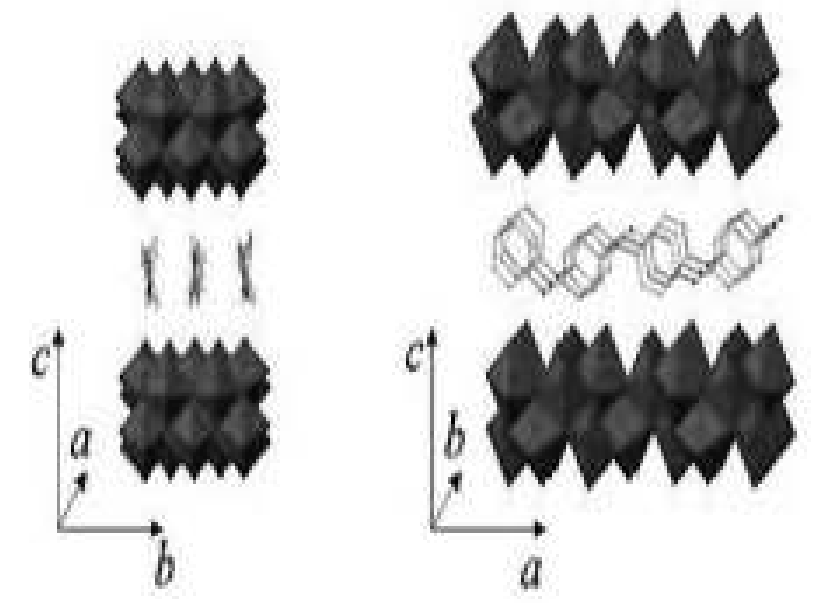

Gambar 3. Ikatan antar partikel yang terjadi pada material nanokomposit 
temperatur yang tinggi dan lain-lain. Akan tetapi karena bahan anorganik adalah sumber yang tidak dapat diperbaharui, dan alasan lingkungan maka penggunaan filler dari bahan limbah pertanian perlu dipertimbangkan karena limbah pertanian berupa biomassa berlimpah di alam, harganya murah, dan tidak merusak lingkungan karena mudah didegradasi, tidak merusak kesehatan bagi pekerja, dan densitasnya sedikit lebih ringan dari pada filler yang menggunakan mineral. Penggunaan organik filler lebih disukai karena mudah di peroleh, dapat diperbaharui keberadaannya dan dapat meningkatkan harga bahan baku serta energi.

Banyak peneliti yang telah mengembangkan bionano komposit dengan mengunakan biomassa yang lebih mengutamakan limbah pertanian yang mengandung biomassa. Hal ini disebabkan oleh banyak tersedianya bahan baku di alam secara komersial, dan telah dilakukan penelitan secara intensif (Hasan dkk., 2010).

Penggunaan biomassa sebagai penguat pada polimer komposit mempunyai banyak keuntungan seperti mempunyai kekuatan tarik dan kekuatan tensil spesifik, densitas rendah, relatif tidak abrasif, tersedia secara luas, dan mudah dimodifikasi dengan permukaan fiber (Ribot dkk., 2011).

Komposit merupakan perpaduan antara dua material atau lebih yang mempunyai perbedaan bentuk, komposisi kimianya, dan tidak saling melarutkan antara materialnya dimana material yang satu berfungsi sebagai penguat dan material yang lainnya berfungsi sebagai pengikat untuk menjaga kesatuan unsur-unsurnya (Gibson dan Ronald, 1994).

Komposit terdiri atas matrik sebagai pengikat dan filler sebagai pengisi komposit. Keunggulan dan keuntungan dari bahan komposit adalah dapat memberikan sifat-sifat mekanik terbaik yang dimiliki oleh komponen penyusunnya, memiliki bobot yang ringan, tahan terhadap korosi, ekonomis, dan tidak sensitif terhadap bahanbahan kimia (Matthews dan Rawling, 1994).

Sifat-sifat fisika dan mekanika dari bionano komposit yaitu sangat tergantung pada jenis matrik yang digunakan, pengisi dan sifat-sifat interaksi bionano filler dan bionano filler-matrik (Hardinnawirda dan Aisya., 2012). Sedangkan menurut Gozdecki, dkk (2012) sifat-sifat mekanika dan fisika dari penguatan komposit biomassa tergantung dari banyak faktor. Misalnya efek pengisi, spesies, ukuran partikel dan coupling agent.

Perkembangan bionanokomposit polimer telah dikembangkan dan dikombinasikan dengan berbagai jenis filler sintetis yang tujuannya untuk meningkatkan sifat-sifat mekanik yang baik sesuai dengan aplikasi yang dikehendaki.

Material bionano komposit polimer yang diperkuat dengan biomassa telah diperlebar dan dikembangkan untuk pengembangan teknologi polimer. Sehingga dihasilkan bionano komposit yang memiliki densitas rendah, biaya yang relatif murah, tidak korosi, komparabel, dan ramah terhadap lingkungan (Hassan dkk, 2010).

Bionanokomposit yang berpenguat sumber biomassa biasanya digunakan untuk sifat-sifat modifikasi optik, mekanika atau permukaan bahan matrik, terutama untuk mengurangi biaya, peforma bahan, memperpanjang umur produk akhir, mengurangi biaya proses, dan meminimasi degradasi selama proses berlangsung (Shaikh dan Channdiwala, 2010), penguatan dan kelenturan, membantu sebagai penahan beban (Zaman dkk., 2011).

Keunggulan lain dari material komposit jika dibandingkan dengan material lainnya adalah penggabungan unsur-unsur yang unggul dari masing-masing unsur pembentuknya tersebut. Sifat material hasil penggabungan ini diharapkan dapat saling melengkapi kelemahan-kelemahan yang ada pada masingmasing material penyusunnya. Sifat-sifat yang dapat diperbaharui antara lain; kekuatan (strenght), kekakuan (stiffness), ketahanan korosi (corrosion resistance), ketahanan gesek/aus (wear resistance), berat (weight), meningkatkan konduktivitas panas dan tahan lama.

Selain filler, sifat bionanokomposit sangat dipengaruhi oleh jenis matriks yang digunakan, dimana matriks berfungsi untuk mengikat 
partikel filler menjadi satu struktur komposit. Gibson (1994) mengatakan bahwa matriks dalam struktur komposit bisa berasal dari bahan polimer, logam, maupun keramik. Matriks memiliki fungsi sebagai pengikat serat menjadi satu kesatuan struktur, melindungi serat dari kerusakan akibat kondisi lingkungan, mentransfer dan mendistribusikan beban ke serat, memberikan beberapa sifat seperti: kekakuan, ketangguhan dan tahanan listrik. Ikatan antar partikel yang terjadi pada material nanokomposit mempunyai peran yang sangat penting dalam peningkatan dan pembatasan sifat material. Partikel-partikel yang berukukuran nano itu memiliki luas permukaan interaksi yang tinggi. Semakin banyak partikel yang berinteraksi, maka semakin kuat pula materialnya. Hal inilah yang membuat ikatan antar partikel semakin kuat, sehingga sifat mekanik materialnya akan meningkat. Akan tetapi penambahan partikel-partikel nano tidak selamanya akan meningkatkan sifat mekaniknya. Ada batasan tertentu dimana saat dilakukan penambahan, justru kekuatan material semakin berkurang. Namun yang umum terjadi material nanokomposit memperlihatkan perbedaan sifat mekanik, listrik, optik, elektrokimia, katalis, dan struktur jika dibandingkan dengan material penyusunnya (Hadiyawarman dkk., 2008).

Berdasarkan matriks yang digunakan, komposit dapat dikelompokkan atas :

1. MMC : Metal Matriks Composite (menggunakan matriks logam). Metal Matriks Composite adalah salah satu jenis komposit yang memiliki matriks logam. MMC mulai dikembangkan sejak tahun 1996. Pada mulanya yang diteliti adalah Continous Filamen MMC yang digunakan dalam industri penerbangan.

2. CMC: Ceramic Matriks Composite (menggunakan matriks keramik). CMC merupakan material dua fasa dengan satu fasa sebagai matriks dimana matriksnya terbuat dari keramik. Penguat yang umum digunakan pada CMC adalah; oksida, carbide, nitride. Salah satu proses pembuatan dari CMC yaitu dengan proses DIMOX yaitu proses pembentukan komposit dengan reaksi oksidasi leburan logam untuk pertumbuhan matriks keramik di sekeliling daerah filler.

3. PMC: Polymer Matriks Composite (menggunakan matriks polimer). Polimer merupakan matriks yang paling umum digunakan pada material komposit. Karena memiliki sifat yang lebih tahan terhadap korosi dan lebih ringan. Matriks polimer terbagi dua yaitu termoset dan termoplastik. Perbedaannya polimer termoset tidak dapat didaur ulang sedangkan termoplastik dapat didaur ulang sehingga lebih banyak digunakan belakangan ini. Jenis-jenis termoplastik yang biasa digunakan adalah polypropylene (PP), polystryrene (PS), polyethylene (PE), dan lain-lain.

Material komposit mempunyai beberapa keuntungan diantaranya bobotnya ringan, mempunyai kekuatan dan kekakuan yang baik, biaya produksi murah serta tahan korosi (Schwartz., 1997). Peter (2002) juga menjelaskan keuntungan dan kerugian dari komposit komersian antara lain :

Keuntungan:

1. Berat berkurang

2. Rasio antara kekuatan atau rasio kekakuan dengan berat tinggi

3. Sifat-sifat yang mampuberadaptasi: Kekuatan atau kekakuan dapat beradaptasi terhadap pengaturan beban

4. Lebih tahan terhadap korosi

5. Kehilangan sebagian sifat dasar material

6. Ongkos manufaktur rendah

7. Konduktivitas termal ataukonduktivitas listrik meningkat atau menurun

\section{Kerugian:}

1. Biaya bertambah untuk bahan baku dan fabrikasi

2. Sifat-sifat bidang melintang lemah

3. Kelemahan matrik, kekerasan rendah

4. Matriks dapat menimbulkan degradasi lingkungan

5. Sulit dalam mengikat

6. Analisa sifat-sifat fisik dan mekanik sulit 
dilakukan, analisis untuk efisiensi damping tidak mencapai konsensus

\section{Metodelogi Penelitian}

\subsection{Bahan dan Alat}

Bahan baku yang digunakan dalam penelitian ini adalah serbuk kayu/ serbuk gergaji yang diperoleh dari industri furniture di Kabupaten Pidie. Peralatan yang digunakan adalah Ball mill dan ayakan ukuran 325 mesh (Macross Testing Sieve).

\subsection{Pembuatan Bionanofiller}

Dipersiapkan bahan bionanofiller yaitu berupa limbah serbuk kayu Meranti. Serbuk kayu Meranti dicuci bersih dan dikeringkan di bawah sinar matahari untuk menghilangkan kadar air. Kemudian dicuci kembali menggunakan aquades dan dikeringkan dalam oven selama 24 jam pada temperatur $80^{\circ} \mathrm{C}$. Serbuk kayu meranti selanjutnya dihaluskan dengan menggunakan blender. Untuk memperoleh ukuran nano serbuk kayu digiling halus di dalam Ball mill sampai mencapai ukuran nano. Selanjutnya serbuk kayu Meranti yang sudah halus diayak dengan menggunakan sieving ukuran 325 mesh. Nanofiller yang dihasilkan selanjutnya dilakukan karakterisasi. Karakterisasi dilakukan dengan FTIR, SEM, XRD, dan densitas partikel.

\subsection{Karakterisasi Filler}

\section{Densitas}

Densitas atau yang biasa disebut sebagai massa jenis merupakan ukuran kerapatan dari suatu material. Densitas juga merupakan salah sifat penting bagi suatu zat. Dimana densitas $(\rho)$ dengan satuan $\mathrm{kg} / \mathrm{m}^{3}$ merupakan perbandingan massa zat, $\mathrm{m}$ dalam $\mathrm{kg}$ terhadap volume zat, $\mathrm{V}$ dalam $\mathrm{m}^{3}$ (Callister, W.D., Jr., 2001).

Analisis densitas serbuk kayu meranti dimulai dengan menimbang sampel (serbuk kayu meranti) sekitar 2 gram. Lalu menimbang massa piknometer kosong sebagai (m1), menimbang massa air yang dimasukkan ke dalam piknometer sebagai (m2), menimbang massa piknometer yang berisi serbuk sebagai (m3), dan menimbang massa serbuk dan air yang terisi d idalam piknometer sebagai (m4). Setalah mendapatkan $\mathrm{m}_{1}, \mathrm{~m}_{2}, \mathrm{~m}_{3}$ dan $\mathrm{m}_{4}$ maka dilakukan perhitungan untuk mengetahui nilai densitasnya serbuk kayu meranti dengan menggunakan persamaan:

dimana:

$$
\rho=\frac{(m 2-m 1)}{(m 3-m 1)+(m 4-m 2)} \times \rho_{\text {air. }}
$$

$$
\begin{aligned}
& \rho=\text { masssa jenis }\left(\mathrm{gr} / \mathrm{cm}^{3}\right) \\
& \mathrm{m}_{1}=\text { massa pikno kosong }+ \text { tutup }(\mathrm{gr}) \\
& \mathrm{m}_{2}=\text { massa pikno kosong }+ \text { tutup }+ \text { bahan }
\end{aligned}
$$

$\mathrm{m}_{3}=$ massa pikono + tutup + fluida $(\mathrm{gr})$

$\mathrm{m}_{4}=$ massa pikno + tutup + bahan + fluida (gr)

\section{SEM}

SEM (Scanning Electron Microscopy) adalah sebuah mikroskop elektron yang didesain untuk menyelidiki permukaan dari objek solid secara langsung.

Tujuan dilakukannya pengujian SEM adalah untuk mengetahui struktur morfologi pada suatu material dalam ukuran mikron. Jenis alat instrumen yang digunakan untuk analisa SEM dalam penelitian ini adalah JEOL JSM 35-C dengan perbesaran 10.000 kali.

Analisis SEM dimulai dengan memasukkan sampel yang akan dianalisis ke vacum column, dimana udara akan dipompa keluar untuk menciptakan kondisi vakum.

Kondisi vakum ini diperlukan agar tidak ada molekul gas yang dapat mengganggu jalannya elektron selama proses berlangsung, lalu elektron ditembakkan dan akan melewati berbagai lensa yang ada menuju ke satu titik di sampel. Selanjutnya sinar elektron tersebut akan dipantulkan ke detektor lalu ke amplifier untuk memperkuat sinyal sebelum masuk ke komputer untuk menampilkan gambar yang diinginkan.

\section{FTIR}

Untuk analisis gugus fungsi filler dilakukan dengan Fourier Transform Infra Red (FTIR). Spektroskopi infra merah adalah suatu metode yang digunakan untuk mengetahui gugus 
fungsional dalam mengidentifikasi senyawa, untuk mengetahui kemurnian, menentukan struktur molekul, dan mempelajari reaksi yang sedang berjalan.

Analisa FTIR dalam penelitian ini dilakukan dengan radiasi elektromagnetik yang berada pada daerah panjang gelombang 0.75 - 1000 $\mu \mathrm{m}$. Untuk analisa gugus fungsi dengan sampel limbah serbuk kayu Meranti dilakukan dengan menggunakan alat Shimadzu Prestige FT-IR 6400 dengan panjang gelombang $4000-400 \mathrm{~cm}^{-1}$.

Langkah-langkah yang dilakukan pada analisis FTIR yaitu sampel yang sudah halus ditimbang dan menimbang sampel padat (bebas air). Selanjutnya mencampur $\mathrm{KBr}$ dan sampel ke dalam mortar dan diaduk hingga keduanya rata. Disiapkan cetakan pellet, mencuci bagian sampel, base dan tablet frame dengan kloroform. Selanjutnya memasukkan sampel $\mathrm{KBr}$ yang telah dicampur dengan set cetakan pellet lalu dihubungkan dengan pompa vakum untuk meminimalkan kadar air.

Selanjutnya meletakkan cetakan pompa hidrolik dan memberikan tekanan sebesar 8 gauge. Dihidupkan pompa vakum selama 15 menit, lalu mematikan pompa vakum. Kemudian menurunkan tekanan dalam cetakan dengan cara membuka keran udara. Setelah itu melepaskan pellet $\mathrm{KBr}$ yang telah terbentuk dan menempatkan pellet $\mathrm{KBr}$ pada tablet holder.

Selanjutnya menghidupkan alat dengan mengalirkansumberaruslistrik, alatinterferometer dan komputer. Mengklik "shortcut FTIR 8400" pada layar komputer yang menandakan program interferometer. Selanjutnya menempatkan sampel dalam alat interferometer, dan mengklik FTIR 8400 pada komputer serta mengisi data. Mengklik "sampel start" untuk memulai, dan untuk memunculkan harga bilangan gelombang mengklik "clac" pada menu, kemudian mengklik "peak table" dan mengklik "OK". Terakhir mematikan komputer, alat interferometer dan sumber listrik.

\section{XRD}

Analisis XRD bertujuan untuk mengkarak- terisasi struktur kristal, ukuran kristal, parameter kisi dan lain-lain (Krisnawan, 2009). Pada penelitian ini analisis struktur kristal filler dilakukan dengan menggunakan alat Shimadzu Maxima XRD-7000. Analisis XRD dilakukan dengan menyiapkan sampel yang akan dianalisis, yaitu sampel yang sudah disinterring pada suhu $800^{\circ} \mathrm{C}, 900^{\circ} \mathrm{C}$ dan $1000^{\circ} \mathrm{C}$. Kemudian direkatkan pada kaca dan dipasang pada tempatnya berupa lempeng tipis berbentuk persegi panjang (sampel holder) dengan lilin perekat.

Memasang sampel yang telah disimpan pada sampel holder kemudian diletakkan pada sampel stand di bagian goniometer. Selanjutnya memasukkan parameter pengukuran pada software pengukuran melalui komputer pengontrol, yaitu meliputi penentuan scan mode, penentuan rentang sudut, kecepatan scan cuplikan, memberi nama cuplikan dan memberi nomor urut file data. Selanjutnya mengoperasikan alat difraktometer dengan perintah "start" pada menu komputer, dimana sinar-x akan meradiasi sampel yang terpancar dari target $\mathrm{Cu}$ dengan panjang gelombang.

Melihat hasil difraksi pada komputer dan intensitas difraksi pada sudut $2 \Theta$ tertentu dapat dicetak oleh mesin printer, kemudian mengambil sampel setelah pengukuran cuplikan selesai. Data yang terekam berupa sudut difraksi $(2 \Theta)$, besarnya intensitas (I), dan waktu pencatatan per langkah (t). Setelah data diperoleh analisis kualitatif dengan menggunakan search match analisys yaitu membandingkan data yang diperoleh dengan data standar (data base PDF = Powder Diffraktion File data Base).

\section{Hasil dan Pembahasan}

\subsection{Densitas}

Hasil analisis densitas serbuk kayu Meranti yang diperoleh adalah sebesar $0,044 \mathrm{gr} / \mathrm{cm}^{3}$. Dari hasil analisis tersebut dapat dikatakan bahwa serbuk kayu memiliki nilai densitas relatif kecil, dimana nilai densitas tersebut berpengaruh terhadap jumlah pori pada suatu bahan. Kecilnya nilai densitas yang diperoleh menjelaskan bahwa semakin besarnya rongga-rongga antar partikel (filler). 


\subsection{Struktur Filler}

Hasil analisa SEM serbuk kayu dapat dilihat pada Gambar 1.

Gambar 1. menunjukkan struktur morfologi permukaan bionanopartikel serbuk kayu Meranti. Hasil SEM terlihat bahwa bionanopartikel sudah berukuran $1 \mu \mathrm{m}$, dengan demikian partikel dari serbuk kayu meranti layak digunakan sebagai pengisi pada polimer komposit. Bionanopartikel serbuk kayu Meranti sukar untuk didefinisikan sebagai individual partikel karena ukurannya yang sangat halus dan berkelompok membentuk agregat.

\subsection{Gugus Fungsi Filler}

Spektrum FTIR yang diperoleh dapat dilihat pada Gambar 2 berikut.

Hasil analisis FTIR serbuk kayu Meranti pada Gambar 2 memperlihatkan bahwa spektra bionanopartikel pada panjang gelombang 3331 $\mathrm{cm}^{-1}$, dan $3305 \mathrm{~cm}^{-1}$ menunjukkan adanya vibrasi ulur dari gugus fungsi-OH yang merupakan unsur penyusun di dalam ligniselulosa. Pada panjang gelombang $2927 \mathrm{~cm}^{-1}$ menunjukkan vibrasi ulur $-\mathrm{CH}_{3}$ dan $-\mathrm{CH}_{2}$, perpanjangan gelombang 1597 $\mathrm{cm}^{-1}$ dan $1508 \mathrm{~cm}^{-1}$ menunjukkan adanya vibrasi $\mathrm{C}=\mathrm{C}$ untuk cincin aromatik, dan juga deformasi $\mathrm{C}-\mathrm{H}$ pada panjang gelombang $1455 \mathrm{~cm}^{-1}$ dan 1425

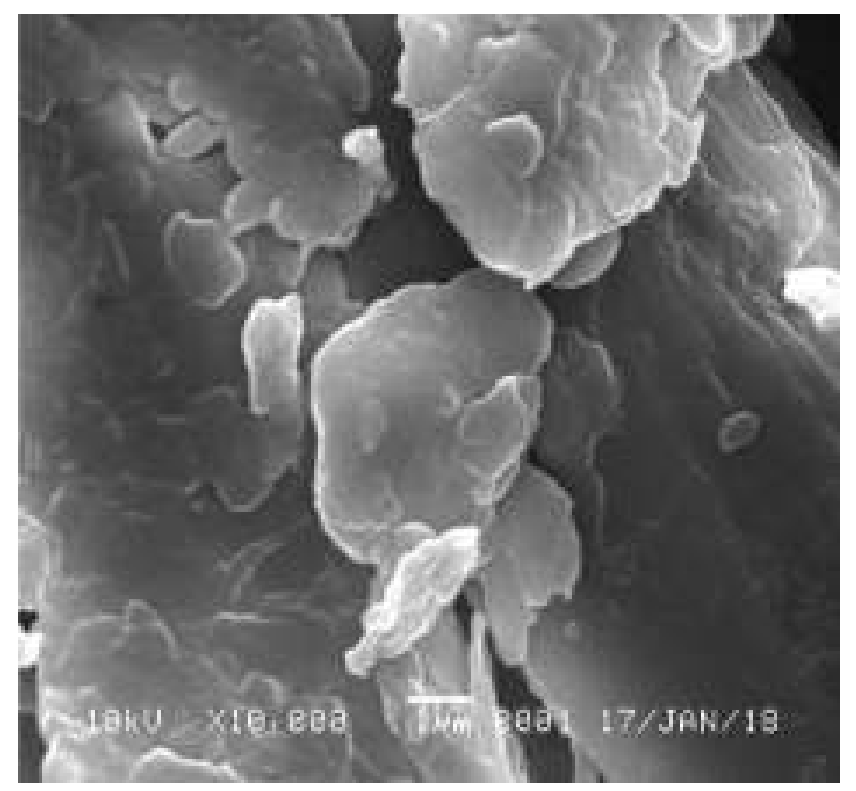

Gambar 1. Analisis SEM bionanopartikel serbuk kayu Meranti

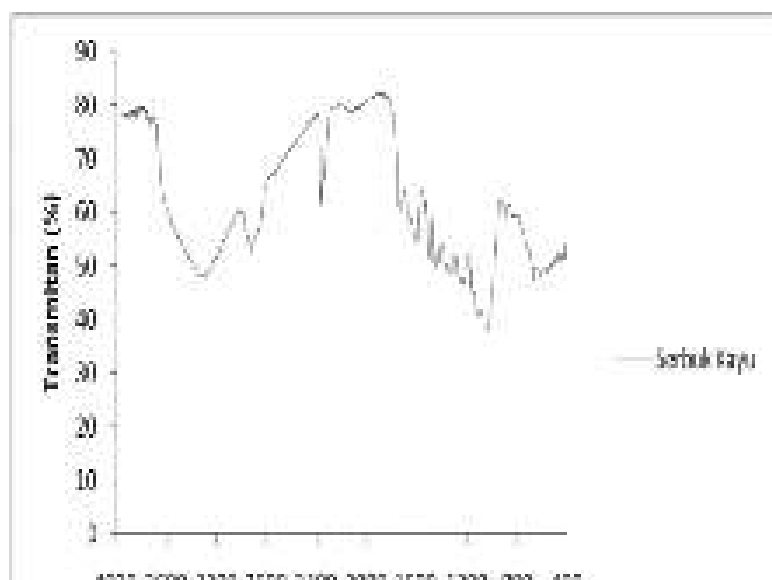

Parime Cetarbat i1: int

Gambar 2. Hasil analisa FTIR serbuk kayu Meranti.

$\mathrm{cm}^{-1}$. Pada panjang gelombang $1325 \mathrm{~cm}^{-1}$ dan $1232 \mathrm{~cm}^{-1}$ masing-masing menunjukkan adanya vibrasi cincin siringil dan vibrasi cincin guaiasil yang merupakan salah satu ciri khas dari kayu yang mempunyai sifat keras. Deformasi C-H dan $\mathrm{C}-\mathrm{O}$ juga ditunjukkan pada panjang gelombang $1055 \mathrm{~cm}-1$ dan $1037 \mathrm{~cm}^{-1}$.

\subsection{Derajat Kristalinitas Filler}

Hasil analisis XRD terlihat pada Gambar 3 sebagai berikut :

Dari Gambar 3. Terlihat adanya puncakpuncak tertinggi yaitu pada $2 \theta: 20,000^{\circ}, 20,700^{\circ}$ dan $22,200^{\circ}$. Puncak maksimum terdapat pada sudut $2 \theta=22,200^{\circ}$ dengan jarak 4,00110 $\AA$,

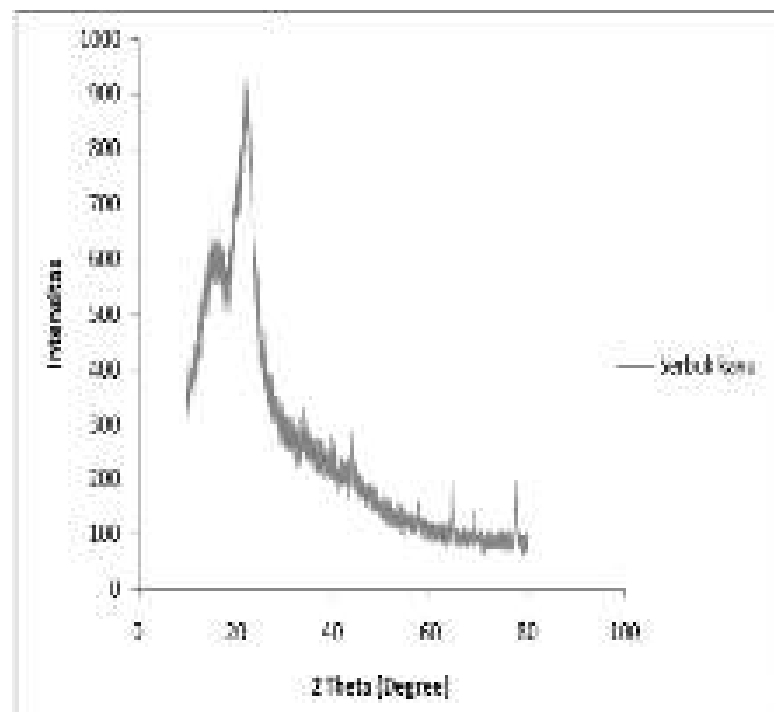

Gambar 3. Analisis XRD bionanopartikel serbuk kayu Meranti. 
dimana menunjukkan adanya fasa karbon (C) yang juga merupakan unsur penyusun utama didalam serbuk kayu Meranti. Miller (1999) juga mengatakan bahwa serbuk $\mathrm{C}$ yang diperoleh dari proses pirolisa kayu Meranti berasal dari kandungan polimer yang terkandung pada sellulosa maupun lignin. Zat lain yang ikut terbentuk selain $\mathrm{C}$ sebagai hasil proses pirolisa yang diidentifikasi oleh proximate analysis sebagai uap air (moisture), abu (ash), dan bahan mudah menguap (volatile matter) (Miller, 1999).

\section{Kesimpulan}

Berdasarkan hasil penelitian dan pembahasan, maka dapat ditarik kesimpulan:

1. Hasil SEM terlihat bahwa bionanopartikel sudah berukuran $1 \mu \mathrm{m}$, dengan demikian partikel dari serbuk kayu Meranti layak digunakan sebagai pengisi (filler) pada polimer komposit.

2. Dari analisa gugus fungsi filler kayu Meranti menunujukkan adanya gugus fungsi $-\mathrm{OH}$ yang merupakan unsur penyusun di dalam ligniselulosa, dan juga terdapat gugus fungsi cincin siringil dan cincin guaiasil yang merupakan salah satu ciri khas dari kayu yang mempunyai sifat keras.

3. Hasil uji XRD juga menunjukkan adanya fasa karbon (C) yang juga merupakan unsur penyusun utama didalam serbuk kayu Meranti.

4. Hasil analisis densitas sebuk kayu yang diperoleh adalah sebesar 0,044 gr/ $\mathrm{cm}^{3}$. Kecilnya nilai densitas yang diperoleh menjelaskan bahwa semakin besarnya rongga-rongga antar pertikel (filler).

\section{Daftar Pustaka}

Azwar (2009), 'Studi Perilaku Mekanik Komposit Berbasis Polyester Yang Diperkuat Dengan Partikel Serbuk Kayu Keras dan Lunak', Journal of Science and Technology, Jurusan Teknik Kimia: Politeknik Negeri Lhokseumawe, 7(16) Desember 2009 ISSN 1693-248X.

Callister, W, D, Jr, (2001), Fundamental of
Materials Science and Engineering Departement of Metallurgical Engineering, John Wiley \& Sons, inc, New York.

Gibson, Ronald, (1994), Principles of Composite Material, New York: Mc Graw Hill.

Gozdecki, C, A, Wilczynski, M, Kociszewski, J, Tomazzewska, \& Zajchowski, S, (2012), Mechanical Properties of WoodPolypropylene Composites With Industrial Wood Particles Of Different Sized, Wood and Fiber Science, 44 (1), pp.1-8.

Hadiyawarman, Agus Rijal, Bebeh, W, Nuryadin, Mikrajuddin, Abdullah, \& Khairurrijal, (2008), 'Fabrikasi Material Nanokomposit Superkuat, Ringan dan Transparan Menggunakan Metode Simple Mixing', Jurnal Nanosains \& Nanoteknologi, 1(1)

Hardinnawirda, K., \& Aisha, I, S, (2012), 'Effect of Rice Husks as Filler In Polymer Matrix Composites', Journal of Mechanical Engineering and Sciences (JMES), 2, pp.181-186.

Hasan, S, H, Ranjan, D, \& Talat, M, (2010), 'Agro-Industrial Waste 'Wheat Bran' for The Biosorptive Remediation of Selenium Through Continuous Up-Flow Fixed-Bed Column', Journal of Hazardous Materials, 181, pp.1134-1142.

Kim, H, S., Choi, S, W, Lee, B, H , Kim, S, Kim, H, J, Cho C, W \& Cho, D, (2007), 'Thermal Properties Of Bio Flour Filled Polypropilene Bio-Composites With Different Pozzolan Contents', Journal of Thermal Analysis and Calorimetry, 89(3), pp.821-82.

Krisnawan, A, (2009), Karakterisasi Sampel Paduan Magnesium Jenis AZ9 1D dengan Berbagai Variasi Waktu Milling Menggunakan XRF dan XRD, Universitas Islam Negeri Syarif Hidayatullah, Jakarta.

La Mantia, F.P., Morreale, M, \& Mohd Ishak, Z.A., (2005), 'Processing and Mechanical Properties of Organic Filler-Polypropylene Composites', Journal of Applied Polymer 
Science, 96, pp.1906-1913.

Matthews F, L \&. Rawling, R,D (1994), 'Composite Material', Engineering Science Technology and Medicine', Chopman \& Hall. London.

Menconen, T , Mussone, P, Alemaskin, K., Sopkow, L., Wolodko, J., Choi, P. \& Bressler, D (2013), 'Biocomposites From Hydrolyzed Waste Proteinaceous Biomass', Mechanical, Thermal And Moisture Absorption Performances, J. Mater. Chem. A, 1, 13186-13196.

Miller, R, B, (1999), Wood Handbook - Wood as an Engineering Material, Madison: Department of Agriculture, Forest Service.

Nurudin, A, Sonief, A, A, \& Atmodjo, Y, W, (2011), 'Karakterisasi Kekuatan Mekanik Komposit Berpenguat Serat Kulit Waru (Hibiscus Tiliaceus) Kontinyu Laminat Dengan Perlakuan Alkali Bermatriks Polyester', Jurnal Rekayasa Teknik Mesin 2(3), pp.209217, Universitas Brawijaya Malang.

Pari, G, (2002,) Teknologi AlternatifPemanfaatan Limbah Industri Pengolahan Kayu, Institut Pertanian Bogor.

Peter, S, T (2002), Composite Material and Process, In: Harper, C, A, Ed, Handbook of Plastics, Elastomers, \& Composite. 4th ed. N. Y.: McGraw-Hill Companies, Inc

Ribot, N, M, H, Ahmad, Z, \& Mustaffa, N, K., (2011), 'Mechanical Properties Of Kenaf Fiber Composite Using Co-Cured InLine Fiber Joint', International Journal of Engineering Science and Technology (IJEST), 3 (4).

Sari, I, T., Dewi, U, R , \& Hengky, (2009), 'Pembuatan Asap Cair Dari Limbah Serbuk Gergajian Kayu Meranti Sebagai Penghilang Bau Lateks', Jurnal Teknik Kimia, 1(16), Januari 2009, Universitas Sriwijaya.

Schwart, M, M, (1984), Composit Material Hand Book, Mc. Graw-Hill Book Company, USA.

Shaikh, A, A., \& Channiwala, S, A., (2010), ' To Study The Characteristics of Jute Polyester Composite For Randomly Distributed Fiber Reinforcement', Proceedings of the World Congress on Engineering, Vol II , WCE 2010.

Slamet, S, (2013), 'Karakterisasi Komposit Dari Serbuk Gergaji Kayu (Sawdust) Dengan Proses Hotpress Sebagai Bahan Baku Papan Partikel', Prosiding SNST Ke-4, Fakultas Teknik Universitas Wahid Hasyim Semarang, pp.1-9.

Sudrajat, R, \& Pari, G, (2011), 'Arang Aktif', TeknologiPengolahandan Masa Depannya. Badan Penelitian dan Pengembangan Kehutanan. Jakarta.

Zaman, H, U, Khan, R, A, Khan, M, A., \& MD. D.H. Beg, (2011), 'Jute-Reinforced Polymer Composite With HDDA Monomer By UV Radiation In The Presence Of Additives', Journal of Thermoplastic composite materials, pp.1-16. 